\title{
Leg length, insulin resistance, and coronary heart disease risk: The Caerphilly Study
}

\author{
G Davey Smith, R Greenwood, D Gunnell, P Sweetnam, J Yarnell, P Elwood
}

\begin{abstract}
Background-Adult height has been inversely associated with coronary heart disease risk in several studies. The mechanism for this association is not well understood, however, and this was investigated by examining components of stature, cardiovascular disease risk factors and subsequent coronary heart disease in a prospective study.
\end{abstract}

Methods-All men aged 45-59 years living in the town of Caerphilly, South Wales were approached, and $2512(89 \%)$ responded and underwent a detailed examination, which included measurement of height and sitting height (from which an estimate of leg length was derived). Participants were followed up through repeat examinations and the cumulative incidence of coronary heart disease-both fatal and non-fatal-over a 15 year follow up period is the end point in this report. Results-Cross sectional associations between cardiovascular risk factors and components of stature (total height, leg length and trunk length) demonstrated that factors related to the insulin resistance syndrome-the homeostasis model assessment of insulin resistance, fasting triglyceride levels and total to HDL cholesterol ratio-were less favourable in men with shorter legs, while showing reverse or no associations with trunk length. Fibrinogen levels were inversely associated with leg length and showed a weaker association with trunk length. Forced expiratory volume in one second was unrelated to leg length but strongly positively associated to trunk length. Other risk factors showed little association with components of stature. The risk of coronary heart disease was inversely related to leg length but showed little association with trunk length.

Conclusion-Leg length is the component of stature related to insulin resistance and coronary heart disease risk. As leg length is unrelated to lung function measures it is unlikely that these can explain the association in this cohort. Factors that influence leg length in adulthood-including nutrition, other influences on growth in early life, genetic and epigenetic influencesmerit further investigation in this regard. The reported associations suggest that pre-adult influences are important in the aetiology of coronary heart disease and insulin resistance.

(F Epidemiol Community Health 2001;55:867-872)
Height in adulthood has been found to be inversely related to coronary heart disease (CHD) risk in various cohort studies. ${ }^{1-6}$ As favourable socioeconomic circumstances are associated with greater height, the relation between height and CHD incidence may be confounded by the effects of childhood and adulthood socioeconomic conditions. While this seems to be partly the case, associations persist after adjustment for socioeconomic circumstances during adult life, ${ }^{67}$ childhood $^{3}$ and both simultaneously. ${ }^{8}$ Birth weight, which is associated with both height ${ }^{9}$ and CHD incidence $^{9}{ }^{10}$ also fails to account for the relation between adulthood height and CHD risk. ${ }^{411}$

Several mechanisms have been suggested for the association between height and CHD risk. These include: fetal growth ${ }^{12}$ and childhood nutrition, ${ }^{13}$ which influence achieved stature and may have long term effects on CHD risk; genetic influences that determine height and health simultaneously ${ }^{2}$; the poorer lung function associated with shorter stature ${ }^{14}$; the lesser diameter of coronary vessels in people of shorter height ${ }^{15}$; and reverse causation, with poor health leading to both shrinkage and increased CHD risk in adulthood. ${ }^{16}$

While it is likely that several of these factors may contribute to the association between height and CHD risk, one approach to further elucidating the relation is to analyse different components of height separately. It has been known for many years that the interruption of growth at any stage results in a relatively long torso and short legs. ${ }^{17}{ }^{18}$ If the rate of growth is sufficiently slowed down, for example by nutritional deficiency, the adult will have relatively short legs. Such proportions have been used as criteria for the study of nutrition and development in childhood, and have been investigated with respect to risk of cancer. ${ }^{1920}$ Recently leg length measured in childhood has been shown to be the component of stature most sensitive to environmental influences ${ }^{21}$ and to demonstrate a strong inverse association with risk of CHD mortality over a 50 year follow up period. ${ }^{13}$ In this paper we relate components of adult stature to $\mathrm{CHD}$ risk in a prospective study, which also allows for the examination of a wide range of potential underlying, confounding or mediating factors.

\section{Methods}

The Caerphilly study is based upon a $100 \%$ sample of men selected from the town of Caerphilly and five adjacent villages. The men were chosen by date of birth so that they were aged 45-59 years when examined between 1979 and 1983. A total of 2512 men were seen $-89 \%$ of the 2818 who were found to be eligible. Full 
Table 1 Pearson's correlation coefficients (and partial correlation coefficients controlling for age) for the correlations between height, trunk, leg length, leg length/trunk ratio and BMI

\begin{tabular}{llllll}
\hline & Height & Trunk length & Leg length & Leg:trunk ratio & BMI \\
\hline Height & 1.00 & & & & \\
Trunk length & $0.78(0.78)$ & 1.00 & & & \\
Leg length & $0.88(0.88)$ & $0.40(0.39)$ & 1.00 & & \\
Leg:trunk ratio & $0.72(0.73)$ & $0.13(0.13)$ & $0.96(0.96)$ & 1.00 & \\
BMI & $-0.013(-0.017)^{\star}$ & $0.17(0.16)$ & $-0.14(-0.15)$ & $-0.20(-0.20)$ & 1.00 \\
\hline
\end{tabular}

All correlations $\mathrm{p}<0.0001$ except ${ }^{\star}$, direct correlation $\mathrm{p}=0.53$, partial correlation $\mathrm{p}=0.40$.

details of screening and follow up procedures have been reported elsewhere. ${ }^{42-24}$ Measurements included blood pressure, total and HDL cholesterol, triglycerides, insulin, glucose, fibrinogen, forced expiratory volume in one second $\left(\mathrm{FEV}_{1}\right)$, own and father's occupational social class, father's unemployment, own employment and smoking behaviour. Lung function was indexed by $\mathrm{FEV}_{1}$ /height squared ${ }^{25}$ and insulin resistance was estimated according to the homeostasis model assessment (HOMA $)^{26}$ as the product of fasting glucose and insulin, divided by the constant 22.5. The higher the value, the greater the level of insulin resistance. These HOMA scores are available for only 2031 men because it was not assessed in diabetic men, those with a fasting blood glucose concentration $\geqslant 8 \mathrm{mmol}$ per litre and participants with missing insulin or glucose measures.

Height was measured in millimetres using a Holtain stadiometer, with care being taken to ensure that the participant was standing upright with his back against the vertical stand, heels against the plate of the base and his chin down so that the middle of his ear was at the same horizontal level as his eyes. The participant was then asked to sit on a stool with his back against the vertical stand of the stadiometer and his sitting height was measured. For the purposes of these analyses leg length has been calculated by subtracting sitting height from standing height. While this contains the stool height - which was the same for each man but was not measured-this will not influence the quintiles or standard deviation of the measure. Height or sitting height were missing on 82 men and one man was a double amputee. Therefore the base sample for the following analyses is 2429 men.

The records of all men at the National Health Service Central Registry were flagged

Table 215 year age adjusted mortality and cumulative incidence of CHD per 100 men, according to different leg length, trunk length, height and leg to trunk length ratio quartiles, with standard errors (SE). P values based on continuous variables for stature, not quartiles

\begin{tabular}{llllll}
\hline & $\begin{array}{l}1-\text { lowest } \\
\text { quartile }\end{array}$ & 2 & 3 & $\begin{array}{l}\text { 4- highest } \\
\text { quartile }\end{array}$ & p Value \\
\hline Leg length & & & & & \\
$\quad$ All deaths (639) & $27.7(1.8)$ & $26.9(1.8)$ & $25.7(1.8)$ & $24.2(1.7)$ & 0.18 \\
CHD deaths (263) & $11.3(1.3)$ & $12.0(1.3)$ & $11.5(1.3)$ & $8.2(1.1)$ & 0.17 \\
$\quad$ All incident CHD (435) & $19.1(1.6)$ & $19.7(1.6)$ & $18.6(1.6)$ & $14.3(1.4)$ & 0.05 \\
Trunk length & & & & & \\
$\quad$ All deaths (639) & $25.8(1.7)$ & $28.9(1.8)$ & $25.8(1.7)$ & $24.7(1.8)$ & 0.82 \\
CHD deaths (263) & $9.9(1.2)$ & $12.0(1.3)$ & $11.2(1.3)$ & $10.3(1.3)$ & 0.49 \\
All incident CHD (435) & $16.6(1.6)$ & $19.9(1.6)$ & $18.2(1.5)$ & $17.2(1.6)$ & 0.40 \\
Height & & & & & \\
All deaths (639) & $26.0(1.7)$ & $28.4(1.8)$ & $25.2(1.7)$ & $24.9(1.8)$ & 0.30 \\
CHD deaths (263) & $10.1(1.2)$ & $12.4(1.3)$ & $11.4(1.3)$ & $9.1(1.2)$ & 0.55 \\
All incident CHD (435) & $17.3(1.5)$ & $20.4(1.6)$ & $19.0(1.5)$ & $15.1(1.5)$ & 0.36 \\
Leg length/trunk length ratio & & & & & \\
All deaths (639) & $28.0(1.7)$ & $26.3(1.7)$ & $25.9(1.8)$ & $24.6(1.7)$ & 0.18 \\
CHD deaths (263) & $11.7(1.3)$ & $10.3(1.2)$ & $12.1(1.3)$ & $8.8(1.2)$ & 0.10 \\
All incident CHD (435) & $19.8(1.6)$ & $17.7(1.6)$ & $18.7(1.5)$ & $15.0(1.5)$ & 0.02 \\
\hline
\end{tabular}

so that notification of death is automatic and a copy of the death certificate is received. Incident $\mathrm{CHD}$ was defined as in previous reports, ${ }^{43}{ }^{24}$ based on admission data to local hospitals, a questionnaire to men (whether still in the original area or having moved) regarding hospital admissions, hospital discharge letters from such admissions, and ECG recordings taken at follow up clinics held at five year intervals from the baseline measurements. The results recorded in this study refer to mortality follow up to the end of 1997 (between 14.25 and 18.25 years follow up) and for non-fatal CHD for an average of 13.75 years follow up.

STATISTICAL METHODS

Pearson's correlation coefficients were calculated between the anthropometric variables. To illustrate the direction and shape of any associations between the four height variables-leg length, trunk length, total height and leg length to trunk length ratio-and other variables, quartiles were used. Age standardised means and prevalence of risk factors were determined for these quartiles. Age standardisation of prevalence was by the direct method in five 3 year age bands, 45-47, 48-50, 51-53, 54-56, and 57-59. Age standardisation of means was carried out with general linear modelling in the SAS procedure GLM. Statistical testing of possible associations was carried out using multiple regression, and using the continuous stature variables. Serum triglyceride and HOMA scores were found to be log normal, the geometric means have been quoted, and the natural log of the variables used in the regression models. Multiple logistic regression was used to explore the effects of other risk factors on the association between CHD and the height variables

\section{Results}

Inter-relations between the various anthropometric measures are presented in table 1. Several of these associations are consequences of variable construction - for example, the sizeable correlations between height and both leg and trunk length reflect the fact that the second are constituents of the first; while body mass index is a measure explicitly computed because of its lack of association with height. However, the relatively low correlation between leg length and trunk length reflect the importance of considering these components separately. Short legs are associated with higher body mass index, while the reverse is the case for trunk length. Men with a high leg to trunk length ratio have a lower body mass index than men with a low ratio.

Total mortality, coronary heart disease mortality and cumulative fatal and non-fatal incident coronary heart disease are displayed according to the anthropometric measures divided into quarters of their distributions in table 2. Longer legs are associated with lower coronary heart disease risk. Height and trunk length are not related to either fatal or total coronary heart disease rates after adjusting for age.

Cardiovascular disease risk factors and demographic data are presented according to quartiles of the anthropometric measures in 
Table 3 Mean or prevalence and standard error (SE) of the mean or prevalence of age adjusted risk factors in men by leg length, sitting height, height and leg: trunk ratio quartiles. Age is the only variable not age adjusted

\begin{tabular}{|c|c|c|c|c|c|}
\hline Variable & 1 - lowest quartile & 2 & 3 & 4 - highest quartile & $\begin{array}{l}p \text { Value for } \\
\text { trend }\end{array}$ \\
\hline \multicolumn{6}{|l|}{ Leg length } \\
\hline Age & $52.5(0.2)$ & $52.5(0.2)$ & $51.9(0.2)$ & $51.4(0.2)$ & 0.0001 \\
\hline Systolic blood pressure $(\mathrm{mm} \mathrm{Hg})$ & $141.8(0.8)$ & $139.9(0.8)$ & $140.8(0.8)$ & $140.6(0.8)$ & 0.43 \\
\hline Diastolic blood pressure $(\mathrm{mm} \mathrm{Hg})$ & $90.0(0.5)$ & $88.0(0.5)$ & $88.4(0.5)$ & $88.3(0.5)$ & 0.19 \\
\hline Total cholesterol $(\mathrm{mmol} / \mathrm{l})$ & $5.79(0.05)$ & $5.74(0.05)$ & $5.64(0.05)$ & $5.66(0.05)$ & 0.037 \\
\hline HDL cholesterol (mmol/1) & $1.10(0.01)$ & $1.15(0.01)$ & $1.12(0.01)$ & $1.12(0.01)$ & 0.56 \\
\hline Total/HDL cholesterol & $5.70(0.08)$ & $5.44(0.08)$ & $5.47(0.08)$ & $5.41(0.08)$ & 0.063 \\
\hline Triglyceride $(\mathrm{mmol} / \mathrm{l})^{\star}$ & $1.82(0.02)$ & $1.66(0.02)$ & $1.65(0.02)$ & $1.62(0.02)$ & 0.0008 \\
\hline Fibrinogen (g/l) & $3.81(0.04)$ & $3.81(0.04)$ & $3.76(0.04)$ & $3.69(0.03)$ & 0.004 \\
\hline $\mathrm{FEV}_{1} /$ height $^{2}\left(\mathrm{cl} / \mathrm{m}^{2}\right)$ & $89.1(1.0)$ & $91.0(1.0)$ & $90.2(1.0)$ & $91.3(0.9)$ & 0.11 \\
\hline Insulin resistance ${ }^{\star}(\mathrm{HOMA})$ & $1.43(0.04)$ & $1.24(0.04)$ & $1.26(0.04)$ & $1.22(0.04)$ & 0.013 \\
\hline Non-manual social class (\%) & $20.2(1.7)$ & $28.8(1.9)$ & $36.1(2.0)$ & $42.7(2.0)$ & 0.0001 \\
\hline Father in non-manual social class (\%) & $8.8(1.2)$ & $8.9(1.2)$ & $12.7(1.4)$ & $18.8(1.6)$ & 0.0001 \\
\hline Father unemployed $(\%)$ & $50.4(2.3)$ & $49.5(2.3)$ & $46.4(2.3)$ & $36.2(2.2)$ & 0.0001 \\
\hline Subject employed at baseline (\%) & $75.2(1.7)$ & $78.9(1.7)$ & $81.3(1.6)$ & $85.9(1.4)$ & 0.0001 \\
\hline Ever smoker (\%) & $84.0(1.5)$ & $84.8(1.5)$ & $85.0(1.4)$ & $82.7(1.5)$ & 0.90 \\
\hline \multicolumn{6}{|l|}{ Trunk length } \\
\hline Age & $53.1(0.2)$ & $52.5(0.2)$ & $51.8(0.2)$ & $51.0(0.2)$ & 0.0001 \\
\hline Systolic blood pressure $(\mathrm{mm} \mathrm{Hg})$ & $140.7(0.8)$ & $140.0(0.8)$ & $140.5(0.8)$ & $141.4(0.8)$ & 0.34 \\
\hline Diastolic blood pressure $(\mathrm{mm} \mathrm{Hg})$ & $88.6(0.5)$ & $88.1(0.5)$ & $88.3(0.5)$ & $89.5(0.5)$ & 0.24 \\
\hline Total cholesterol (mmol/l) & $5.75(0.05)$ & $5.80(0.05)$ & $5.67(0.05)$ & $5.64(0.05)$ & 0.016 \\
\hline HDL cholesterol (mmol/1) & $1.16(0.01)$ & $1.13(0.01)$ & $1.12(0.01)$ & $1.08(0.01)$ & 0.0001 \\
\hline Total/HDL cholesterol & $5.40(0.09)$ & $5.56(0.08)$ & $5.45(0.08)$ & $5.61(0.09)$ & 0.062 \\
\hline Triglyceride $(\mathrm{mmol} / \mathrm{l})^{\star}$ & $1.66(0.02)$ & $1.69(0.02)$ & $1.65(0.02)$ & $1.76(0.02)$ & 0.055 \\
\hline Fibrinogen $(\mathrm{g} / \mathrm{l})$ & $3.82(0.04)$ & $3.76(0.04)$ & $3.76(0.03)$ & $3.73(0.04)$ & 0.093 \\
\hline $\mathrm{FEV}_{1} /$ height $^{2}\left(\mathrm{cl} / \mathrm{m}^{2}\right)$ & $86.2(1.0)$ & $90.1(0.9)$ & $91.4(0.9)$ & $93.5(1.0)$ & 0.0001 \\
\hline Insulin resistance ${ }^{\star}(\mathrm{HOMA})$ & $1.23(0.04)$ & $1.24(0.04)$ & $1.26(0.04)$ & $1.45(0.04)$ & 0.0025 \\
\hline Non-manual social class (\%) & $24.3(1.8)$ & $29.5(1.9)$ & $31.7(1.9)$ & $43.7(2.1)$ & 0.0001 \\
\hline Father in non-manual social class (\%) & $11.0(1.4)$ & $11.4(1.4)$ & $13.1(1.4)$ & $14.4(1.5)$ & 0.006 \\
\hline Father unemployed (\%) & $47.8(2.4)$ & $47.8(2.3)$ & $43.9(2.2)$ & $42.1(2.3)$ & 0.0001 \\
\hline Subject employed at baseline (\%) & $76.5(1.8)$ & $79.5(1.6)$ & $81.3(1.6)$ & $82.8(1.6)$ & 0.012 \\
\hline Ever smoker $(\%)$ & $85.9(1.5)$ & $84.1(1.5)$ & $82.5(1.5)$ & $84.3(1.5)$ & 0.22 \\
\hline \multicolumn{6}{|l|}{ Height } \\
\hline Age & $53.0(0.2)$ & $52.6(0.2)$ & $51.6(0.2)$ & $51.2(0.2)$ & 0.0001 \\
\hline Systolic blood pressure $(\mathrm{mm} \mathrm{Hg})$ & $141.6(0.8)$ & $140.0(0.8)$ & $140.0(0.8)$ & $141.3(0.8)$ & 0.96 \\
\hline Diastolic blood pressure $(\mathrm{mm} \mathrm{Hg})$ & $89.6(0.5)$ & $88.1(0.5)$ & $87.9(0.5)$ & $89.0(0.5)$ & 0.76 \\
\hline Total cholesterol $(\mathrm{mmol} / \mathrm{l})$ & $5.74(0.05)$ & $5.78(0.05)$ & $5.69(0.05)$ & $5.64(0.05)$ & 0.008 \\
\hline HDL cholesterol $(\mathrm{mmol} / \mathrm{l})$ & $1.14(0.01)$ & $1.13(0.01)$ & $1.11(0.01)$ & $1.11(0.01)$ & 0.047 \\
\hline Total/HDL cholesterol & $5.47(0.09)$ & $5.55(0.08)$ & $5.57(0.08)$ & $5.45(0.08)$ & 0.75 \\
\hline Triglyceride $(\mathrm{mmol} / \mathrm{l})^{\star}$ & $1.70(0.02)$ & $1.73(0.02)$ & $1.68(0.02)$ & $1.65(0.02)$ & 0.19 \\
\hline Fibrinogen $(\mathrm{g} / \mathrm{l})$ & $3.77(0.04)$ & $3.81(0.04)$ & $3.79(0.03)$ & $3.69(0.03)$ & 0.005 \\
\hline $\mathrm{FEV}_{1} /$ height $^{2}\left(\mathrm{cl} / \mathrm{m}^{2}\right)$ & $88.2(1.0)$ & $89.2(1.0)$ & $92.2(1.0)$ & $91.8(0.9)$ & 0.0001 \\
\hline Insulin resistance $(\mathrm{HOMA})$ & $1.35(0.04)$ & $1.23(0.04)$ & $1.30(0.04)$ & $1.27(0.04)$ & 0.89 \\
\hline Non-manual social class (\%) & $20.1(1.7)$ & $28.9(1.9)$ & $35.8(2.0)$ & $43.1(2.1)$ & 0.0001 \\
\hline Father in non-manual social class (\%) & $7.7(1.2)$ & $11.9(1.4)$ & $13.8(1.5)$ & $16.0(1.6)$ & 0.0001 \\
\hline Father unemployed (\%) & $49.7(2.4)$ & $49.7(2.3)$ & $42.4(2.3)$ & $39.2(2.2)$ & 0.0001 \\
\hline Subject employed at baseline (\%) & $75.2(1.8)$ & $79.9(1.6)$ & $80.8(1.6)$ & $85.3(1.5)$ & 0.0001 \\
\hline Ever smoker (\%) & $82.7(1.6)$ & $85.7(1.5)$ & $83.9(1.5)$ & $83.7(1.5)$ & 0.47 \\
\hline \multicolumn{6}{|l|}{ Leg length/trunk length ratio } \\
\hline Age & $52.3(0.2)$ & $52.4(0.2)$ & $51.9(0.2)$ & $51.7(0.2)$ & 0.011 \\
\hline Systolic blood pressure $(\mathrm{mm} \mathrm{Hg})$ & $141.7(0.8)$ & $140.3(0.8)$ & $141.0(0.8)$ & $140.2(0.8)$ & 0.27 \\
\hline Diastolic blood pressure $(\mathrm{mm} \mathrm{Hg})$ & $90.1(0.5)$ & $88.0(0.5)$ & $88.3(0.5)$ & $88.2(0.5)$ & 0.074 \\
\hline Total cholesterol $(\mathrm{mmol} / \mathrm{l})$ & $5.78(0.05)$ & $5.72(0.05)$ & $5.69(0.05)$ & $5.64(0.05)$ & 0.13 \\
\hline HDL cholesterol (mmol/1) & $1.09(0.01)$ & $1.13(0.01)$ & $1.14(0.01)$ & $1.13(0.01)$ & 0.047 \\
\hline Total/HDL cholesterol & $5.74(0.08)$ & $5.43(0.08)$ & $5.46(0.08)$ & $5.38(0.08)$ & 0.013 \\
\hline Triglyceride $(\mathrm{mmol} / \mathrm{l})^{\star}$ & $1.83(0.02)$ & $1.66(0.02)$ & $1.64(0.02)$ & $1.60(0.02)$ & 0.0001 \\
\hline Fibrinogen $(\mathrm{g} / \mathrm{l})$ & $3.80(0.03)$ & $3.79(0.03)$ & $3.76(0.03)$ & $3.70(0.04)$ & 0.012 \\
\hline $\mathrm{FEV}_{1} /$ height $^{2}\left(\mathrm{cl} / \mathrm{m}^{2}\right)$ & $90.2(1.0)$ & $90.6(1.0)$ & $90.4(1.0)$ & $90.2(1.0)$ & 0.89 \\
\hline Insulin resistance ${ }^{\star}(\mathrm{HOMA})$ & $1.47(0.04)$ & $1.25(0.04)$ & $1.21(0.04)$ & $1.21(0.04)$ & 0.0004 \\
\hline Non-manual social class (\%) & $22.2(1.7)$ & $28.0(1.8)$ & $37.3(2.0)$ & $40.7(2.0)$ & 0.0001 \\
\hline Father in non-manual social class (\%) & $8.4(1.2)$ & $10.7(1.3)$ & $11.7(1.4)$ & $18.5(1.7)$ & 0.0001 \\
\hline Father unemployed (\%) & $48.9(2.3)$ & $52.4(2.3)$ & $44.5(2.3)$ & $36.0(2.2)$ & 0.0001 \\
\hline Subject employed at baseline (\%) & $75.6(1.7)$ & $78.0(1.7)$ & $82.8(1.5)$ & $85.0(1.5)$ & 0.0001 \\
\hline Ever smoker (\%) & $82.5(1.5)$ & $86.3(1.4)$ & $84.1(1.5)$ & $83.5(1.5)$ & 0.82 \\
\hline
\end{tabular}

${ }^{\star}$ Geometric means, standard errors refer to logged data.

table 3. Blood pressure is not strongly related to any anthropometric measure while total cholesterol levels are inversely related to all the anthropometric measures. Lung function is positively related to both overall height and to trunk length, but not to leg length. Factors related to the insulin resistance syndromeHOMA scores, triglyceride levels and total/ HDL cholesterol ratio-are associated in opposite directions with leg and trunk length. Men with shorter legs are more liable to have high HOMA scores and high triglyceride levels while associations in the opposite direction are seen with trunk length. Height, on the other hand, tends to be unrelated to these measures.
All anthropometric measures are related to the occupational social class of the men, the occupational social class of the father's of the men and whether their fathers had been unemployed at any time during their childhood. Indicators of childhood socioeconomic circumstances were particularly strongly related to leg length. All anthropometric measures were positively related to the men being in employment. Smoking behaviour was unrelated to any of the anthropometric measures.

Risk of incident CHD in relation to the anthropometric measures, both before and after various adjustments for potential confounding or mediating factors, is detailed in 
table 4. Leg length and leg length to trunk length ratio were both inversely associated with CHD risk. Adjustment for various potential confounding or intermediary factors had little influence on the effect estimates, although the level of significance was attentuated.

\section{Discussion}

Height has been inversely related to CHD risk in many studies ${ }^{1-61112141627}$ and a higher prevalence and greater severity of coronary atherosclerosis found at arteriography has also been reported among shorter men. ${ }^{28}$ The weak and non-significant inverse association between overall height and incident CHD seen in this longer follow up of the Caerphilly Study represents an attenuation of the stronger inverse association seen over a five year follow up. ${ }^{4}$ A similar decrease in the magnitude of the inverse association between height and CHD mortality with longer follow up has been seen in the Whitehall Study ${ }^{16}$ and it was there postulated that this may reflect some of the
KEY POINTS

- Height is inversely related to CHD risk in many studies.

- We demonstrate that the inverse association is specific to leg length, and is not seen for trunk length.

- Leg length is also inversely associated with components of the insulin resistance syndrome, while trunk length is unrelated to these components.

- Leg length may serve as an indicator of exposures acting during childhood.

height-CHD association being attributable to greater reductions in height occurring with aging among ill people. As the group of already sick people decreases in size because of selective mortality this group will have increasingly less influence on height-CHD incidence associations and the attenuation with follow up that is seen would be expected. While this may

Table 4 Odds ratios for CHD incidence for increase in one standard deviation of leg length, trunk length, height and leg length/trunk length ratio

\begin{tabular}{|c|c|c|c|c|c|}
\hline \multirow[b]{2}{*}{ Variables in model } & \multicolumn{5}{|l|}{ Leg length } \\
\hline & $\begin{array}{l}\text { Number of men with } \\
\text { full data on variables } \\
\text { considered }\end{array}$ & $\begin{array}{l}\text { Unadjusted odds ratio for } \\
\text { increase in leg length of } \\
\text { one standard deviation * }\end{array}$ & $95 \% C I$ & $\begin{array}{l}\text { Adjusted odds ratio for } \\
\text { increase in leg length of } \\
\text { one standard deviation * }\end{array}$ & $95 \% C I$ \\
\hline Anthropometric variablest & 2427 & 0.90 & {$[0.81,1.00]$} & 0.90 & {$[0.80,1.01]$} \\
\hline $\mathrm{CHD}$ risk factors $\mathbb{\Omega}$ & 2152 & 0.89 & {$[0.79,1.00]$} & 0.94 & {$[0.84,1.06]$} \\
\hline Insulin resistance & 1904 & 0.88 & {$[0.78,0.99]$} & 0.89 & {$[0.79,1.00]$} \\
\hline 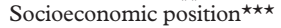 & 2370 & 0.90 & {$[0.81,1.00]$} & 0.91 & {$[0.82,1.02]$} \\
\hline \multirow[t]{3}{*}{ All listed variablestt† } & 1771 & 0.87 & {$[0.76,0.99]$} & 0.88 & {$[0.76,1.02]$} \\
\hline & \multicolumn{5}{|l|}{ Trunk length } \\
\hline & $\begin{array}{l}\text { Number of men with } \\
\text { full data on variables } \\
\text { considered }\end{array}$ & $\begin{array}{l}\text { Unadjusted odds ratio for } \\
\text { increase in trunk length } \\
\text { of one standard deviation } \neq\end{array}$ & $95 \% C I$ & $\begin{array}{l}\text { Adjusted odds ratio for } \\
\text { increase in trunk length } \\
\text { of one standard deviation } \neq\end{array}$ & $95 \% C I$ \\
\hline Anthropometric variables $₫$ & 2427 & 1.05 & {$[0.94,1.16]$} & 1.07 & {$[0.95,1.20]$} \\
\hline $\mathrm{CHD}$ risk factors $\$ \mathbb{8}$ & 2152 & 1.04 & {$[0.93,1.17]$} & 1.08 & {$[0.96,1.22]$} \\
\hline Insulin resistance & 1904 & 1.01 & {$[0.89,1.14]$} & 0.98 & {$[0.86,1.10]$} \\
\hline Socioeconomic position $\star \star \star \star$ & 2370 & 1.06 & {$[0.95,1.18]$} & 1.08 & {$[0.96,1.20]$} \\
\hline \multirow[t]{2}{*}{ All listed variablest†† } & 1771 & 1.03 & {$[0.91,1.17]$} & 1.12 & {$[0.97,1.30]$} \\
\hline & \multicolumn{5}{|l|}{ Height } \\
\hline Variables in model & $\begin{array}{l}\text { Number of men with } \\
\text { full data on variables } \\
\text { considered }\end{array}$ & $\begin{array}{l}\text { Unadjusted odds ratio for } \\
\text { increase in height of one } \\
\text { standard deviation }\end{array}$ & $95 \% C I$ & $\begin{array}{l}\text { Adjusted odds ratio for } \\
\text { increase in height of one } \\
\text { standard deviation }\end{array}$ & $95 \% C I$ \\
\hline Anthropometric variables ${ }^{\star \star}$ & 2427 & 0.95 & {$[0.86,1.06]$} & 1.05 & {$[0.89,1.23]$} \\
\hline $\mathrm{CHD}$ risk factors $\mathbb{\Omega}$ & 2152 & 0.94 & {$[0.84,1.06]$} & 1.00 & {$[0.88,1.12]$} \\
\hline Insulin resistance $\mid$ ๆ & 1904 & 0.92 & {$[0.81,1.04]$} & 0.91 & {$[0.80,1.03]$} \\
\hline Socioeconomic position $\star \star \star \star$ & 2370 & 0.96 & {$[0.86,1.07]$} & 0.98 & {$[0.87,1.09]$} \\
\hline \multirow[t]{3}{*}{ All listed variablest†† } & 1771 & 0.92 & {$[0.81,1.05]$} & 1.12 & {$[0.91,1.36]$} \\
\hline & \multicolumn{5}{|c|}{ Leg length/trunk length ratio } \\
\hline & $\begin{array}{l}\text { Number of men with } \\
\text { full data on variables } \\
\text { considered }\end{array}$ & $\begin{array}{l}\text { Unadjusted odds ratio for } \\
\text { increase in leg } \\
\text { length/trunk length ratio of } \\
\text { one standard deviationtt }\end{array}$ & $95 \% C I$ & $\begin{array}{l}\text { Adjusted odds ratio for } \\
\text { increase in leg } \\
\text { length/trunk length ratio of } \\
\text { one standard deviationtt }\end{array}$ & $95 \% C I$ \\
\hline 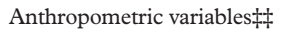 & 2427 & 0.88 & {$[0.80,0.98]$} & 0.88 & {$[0.75,1.03]$} \\
\hline $\mathrm{CHD}$ risk factors $\mathbb{\Omega}$ & 2152 & 0.87 & {$[0.77,0.98]$} & 0.92 & {$[0.81,1.03]$} \\
\hline Insulin resistance & 1904 & 0.87 & {$[0.77,0.98]$} & 0.89 & {$[0.79,1.01]$} \\
\hline 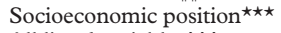 & 2370 & 0.88 & {$[0.79,0.98]$} & 0.89 & {$[0.80,1.00]$} \\
\hline All listed variables††† & 1771 & 0.86 & {$[0.75,0.97]$} & 0.83 & {$[0.68,1.01]$} \\
\hline
\end{tabular}

*Odds ratio for increase in leg length of one standard deviation $(4.4 \mathrm{~cm})$, adjusted for age. †Anthropometric variables in the model: trunk length. $¥$ Odds ratio for increase in sitting height of one standard deviation $(3.3 \mathrm{~cm}$ ), adjusted for age. SAnthropometric variables in the model: leg length. ๆOdds ratio for increase in height of one standard deviation $(6.5 \mathrm{~cm})$, adjusted for age. ${ }^{\star \star}$ Anthropometric variables in the model: sitting height. ††Odds ratio for increase in leg length/trunk length ratios of one standard deviation (3.3 cm), adjusted for age. \$Anthropometric variables in the model: height. $\$ \varsigma \mathrm{CHD}$ risk factors in the model: $\mathrm{BMI}, \mathrm{FEV} / \mathrm{H}^{2}$, cholesterol, fibrinogen, diastolic blood pressure, ever smoked, currently smoke. 9 Insulin resistance factors in the model: HOMA, log triglycerides, HDL cholesterol. ${ }^{\star \star \star}$ Indicators of socioeconomic position in the model: own social class, father's social class (including a category for not known), father unemployed (including a category for not known). $+\dagger \dagger$ All variables from all four categories entered in the model. 
contribute to the association between overall height and CHD being weaker at this longer follow up in the Caerphilly Study, it is unlikely to account for an inverse association between leg length and CHD incidence. Longitudinal studies examining reductions in height with age suggest that this occurs preferentially in trunk rather than leg component of total height, probably due both to shrinkage in the vertebral column and scoliosis. ${ }^{29}$ Thus associations between leg length, which is less affected by aging, and CHD incidence are unlikely to be confounded by adult disease processes leading to shrinkage in those with ill health. ${ }^{16}$

The specific association of leg length and CHD incidence has implications for other potential mechanisms linking height and CHD risk. In this study we see that trunk length, rather than leg length, is positively associated with lung function. This is the expectation that follows from simple mechanical considerations. If the association between height and $\mathrm{CHD}$ risk were mediated through lung function, as has been suggested, ${ }^{14}$ it would be expected that trunk length, rather than leg length, would be the important component of total height. The fact that the reverse is the case suggests that the lung function hypothesis cannot provide a full explanation of the association between height and CHD risk. Inhibited fetal development, reflected in lower height in adulthood, has been advanced to explain the association between height and CHD. The hypothesis here is that it is poor fetal development that is the fundamental causal factor, and height serves as a marker of this. However, the correlations between birth weight, the indicator of fetal development used in many of the prospective studies investigating the fetal origins of $\mathrm{CHD}$, and the two components of height are similar, $r=0.17$ for trunk length and $r=0.12$ for leg length - in this study. Data from other studies also demonstrate similar correlations of birth weight (and birth weight adjusted for birth length) with trunk length and leg length. ${ }^{30}$ If impaired fetal development underlay the height-CHD associations it would be expected that both components of height would have similar associations with CHD. Again this is counter to the results we obtained.

Leg length seems to serve as an indicator of nutritional status in childhood. ${ }^{31}$ It is the component of overall height that grows proportionately more in the years up to puberty, ${ }^{32}$ as shown by changes in the sitting height: height ratio from birth to adulthood from around 0.66 to around $0.52^{33}$ and secular increases in height are thought to be largely attributable to leg length increases. ${ }^{34}$ Thus, in the observed relations between leg length and CHD mortality, leg length may be acting as a sensitive marker for environmental exposures in childhood leading both to growth retardation and later predisposition to CHD.

Other explanations for the height-CHD relation may be classified under two headingsconfounding and mechanical. Height-CHD relations may be confounded by adult risk factors. For example, children exposed to environmental factors that retard growth may be more likely to become adult smokers ${ }^{35}$; similarly, taller children are more likely to experience upward social mobility ${ }^{36}$ and adults in upper socioeconomic groups are at reduced CHD risk. Adjustment for both adult risk factors and social class partially attenuated some of the hazard ratios seen in our analyses. Attenuation with respect to adult risk factors may be because alterations of these are the mechanism through which childhood exposures affect adult CHD risk. Thus, rather than adjusting for a confounding factor, one is adjusting for a risk factor lying on the causal pathway of the observed associations, thereby diminishing "true" effects. Mechanical explanations suggest that reduced stature is associated with diminished coronary artery lumen diameter and thereby greater risk of occlusion. ${ }^{15}$ If this explanation were valid, one might expect to see stronger relations with trunk length, as this may more directly relate to body mass and hence heart and coronary size. This was not found in our analyses.

Height in adulthood has been inversely associated with the risk of adult onset diabetes and impaired glucose tolerance in some ${ }^{37} 3839$ but not all $^{40}$ previous studies. This association could reflect common genetic factors influencing both height and later glucose tolerance; intrauterine development and its associations with adulthood height and later glucose tolerance, or childhood circumstances that influence final attained height and later glucose tolerance. Evidence that the inverse association between height and glucose tolerance is independent of birth weight has been interpreted as indicating that the association does not simply reflect the influence of intrauterine environment. In our analyses we demonstrate clearly that the association between stature and insulin resistancetogether with other components of the metabolic syndrome, including triglyceride levels and obesity - are linked specifically to leg length. As birth weight is similarly associated with height, with leg length and trunk length, the specific associations between leg length and components of the metabolic syndrome are unlikely to reflect the common influence of intrauterine development, which is reflected in birth weight. However, the relevance of insulin resistance ${ }^{41}$ and the components of the metabolic syndrome for subsequent development of CHD have been questioned among non-diabetics. ${ }^{42}$ Statistical adjustment for components of the insulin resistance syndrome did not greatly attenuate the association between leg length and incident CHD. Thus it seems that additional mechanisms link leg length to risk of CHD.

Adverse social circumstances in childhood are related to increased risk of CHD mortality, ${ }^{43}$ and to components of the metabolic syndrome. ${ }^{44}$ Leg length and leg length to trunk length ratio, both in childhood and in adulthood, may reflect the influence of growth patterns, which, in turn influence later disease risk. In both this study and in the Boyd Orr cohort - in which leg length was measured in childhood-the association between components of stature and adult disease risk were statistically independent of socioeconomic indicators in both childhood and in adulthood. Thus 
the leg length association with adulthood disease does not appear to simply reflect confounding by social circumstances.

Leg length and leg length to trunk length ratio in adulthood seem to be influenced by factors constraining early childhood growth (poorer socioeconomic circumstances result in shorter legs and a lower leg length to trunk length ratio), however later puberty (which may also reflect adverse circumstances) results in greater leg length to trunk length ratios. ${ }^{45}$ Thus leg length and leg to trunk length ratio in adulthood will be a less useful indicator of childhood circumstances than leg length measured in childhood. This may explain why the associations with CHD were of greater magnitude in the Boyd Orr cohort, in which anthropometric measurements were taken in childhood, than in this study. ${ }^{13}$

In conclusion, leg length is inversely associated with the risk of CHD and with components of the insulin resistance syndrome among adults. This provides supportive evidence for the hypothesis that impaired growth during childhood increases the risk of these conditions. The finding should, however, be considered in the light of evidence suggesting that high calorie intake in childhood, longer legs in childhood and greater final achieved stature are associated with an increased risk of non-smoking relating cancers. ${ }^{6} 161946$ Further research is required to delineate the overall influence of encouraged growth in childhood on adult health.

We thank Claire Snadden for help with manuscript preparation.

Funding: the Caerphilly study was supported by the Medica Research Council but these analyses were unfunded.

Conflicts of interest: none.

1 Greig M, Pemberton J, Hay I, et al. A prospective study of the development of coronary heart disease in a group of 1202 middle-aged men. $\mathcal{F}$ Epidemiol Community Health 1202 middle-a

2 Waaler HT, Height, weight and mortality. Acta Med Scand 1984; (suppl).

3 Notkola V, Punsar S, Karvonen MJ, et al. Socio-economic conditions in childhood and mortality and morbidity caused by coronary heart disease in adulthood in rural Finland. Soc Sci Med 1985;21:517-23.

4 Yarnell JWG, Limb ES, Layzell JM, et al. Height: a risk marker for ischaemic heart disease: prospective results from the Caerphilly and Speedwell heart disease studies. Eur Heart $\mathcal{F}$ 1992;13:1602-5.

5 Hebert PR, Rich-Edwards JW, Manson JE, et al. Height and incidence of cardiovascular disease in male physicians. Circulation 1993;88:1437-43.

6 Davey Smith G, Hart C, Upton M, et al. Height and risk of death among men and women: aetiological implications of associations with cardiorespiratory disease and cancer associations with cardiorespiratory disease and cancer

7 Davey Smith G, Shipley MJ, Rose G. Magnitude and causes of socioeconomic differentials in mortality: further evidence from the Whitehall Study. F Epidemiol Community dence from the Whiteh
Health 1990;44:265-70.

Health 1990;44:265-70.
8 Peck ANM, Văgerö D. Adult body height, self perceived health and mortality in the Swedish population. F Epidemiol Community Health 1989;43:380-4.

9 Frankel S, Elwood P, Sweetnam P, et al. Birthweight, adult risk factors and incident coronary heart disease: The Caerphilly Study. Public Health 1996;110:139-43.

10 Barker DJP. Mothers, babies, and disease in later life. London: BMJ Books, 1994.

11 Rich-Edwards JW, Manson JE, Stampfer MJ, et al. Height and risk of cardiovascular disease in women. $A m$ Epidemiol 1995;142:909-17.

12 Barker DJP, Osmond C, Golding J. Height and mortality in the counties of England and Wales. Ann Hum Biol 1990;17: $1-6$.

13 Gunnell D, Davey Smith G, Frankel S, et al. Childhood leg length and adult mortality: follow up of the Carnegie (Boyd Orr) Survey of diet and health in pre-war Britain. $\mathcal{F}$ Epidemiol Community Health 1998;52:142-52.

14 Walker M, Shaper AG, Phillips AN, et al. Short stature, lung function and the risk of a heart attack. Int $\mathcal{f}$ Epidemiol 1989;18:602-6.
15 Palmer JR, Rosenberg L, Shapiro S. Stature and the risk of myocardial infarction in women. Am f Epidemiol 1990;132: $27-32$.

16 Leon DA, Davey Smith G, Shipley M, et al. Adult height and mortality in London: early life, socioeconomic confounding, or shrinkage? f Epidemiol Community Health 1995;49: 5-9.

17 Leitch I. Growth and health. Br f Nutr 1951;5:142-51.

18 Mitchell HS. Nutrition in relation to stature. $f$ Am Diet Assoc 1962;40:521-4.

19 Gunnell DJ, Davey Smith G, Holly JMP, et al. Leg length and risk of cancer in the Boyd Orr cohort. BMF 1998;317: $1350-1$.

20 Albanes D, Jones DY, Schatzhin A, et al. Adult stature and risk of cancer. Cancer Res 1988;48:1658-62.

21 Gunnell DJ, Davey Smith G, Frankel SJ, et al. Socioeconomic and dietary influences on leg length and trunk length in childhood: a reanalysis of the Carnegie (Boyd Orr) survey of diet and health in prewar Britain (1937-39). Paediatr Perinat Epidemiol 1998;12 (suppl 1):96-113.

22 The Caerphilly and Speedwell Collaborative Group. Caerphilly and Speedwell Collaborative Heart Disease Studies. 7 Epidemiol Community Health 1984;38:259-62.

23 Yarnell JWG, Sweetnam PM, Marks V, et al. Insulin in ischaemic heart disease: are associations explained by triglyceride concentrations? The Caerphilly prospective study. Br Heart ₹ 1994;71:293-6.

24 Yarnell JWG, Baker IA, Sweetnam PM, et al. Fibrinogen, viscosity and white blood cell count are major risk factors for ischaemic heart disease: the Caerphilly and Speedwell collaborative heart disease studies. Circulation 1991;83: 836-44.

25 Cole TJ. Linear and proportional regression models in the prediction of ventilatory function. Fournal of the Royal Statistical Society 1975;138:297-338.

26 Matthews DR, Hosker JP, Rudenski AS, et al. Homeostasis model assessment: insulin resistance and beta-cell function from fasting plasma glucose and insulin concentrations in man. Diabetologia 1985;28:412-19.

27 Williams SRP, Jones E, Bell W, et al. Body habitus and coronary heart disease in men. Eur Heart $\mathcal{f}$ 1997;18:376-93.

28 Nwasokwa ON, Weiss M, Gladstone C, et al. Higher prevalence and greater severity of coronary disease in short versus tall men referred for coronary arteriography. Am Heart f 1997; 133:147-52.

29 Friedlaender JS, Costa PT, Bosse R, et al. Longitudinal physique changes among healthy white veterans in Boston. Hum Biol 1977;49:541-58.

30 Gunnell D, Davey Smith G, McConnachie A, et al. Separating in-utero and postnatal influences on later disease. Lancet 1999;354:1526-7.

31 Gunnell D. Commentary: Early insights into height, leg length, proportionate growth and health. Int $\mathcal{F}$ Epidemiol 2001;30:221-2.

32 Martorell R, Malina RM, Castillo RO, et al. Body proportion in three ethnic groups: children and youths 2-17 years in NHANES II and HHANES. Hum Biol 1988; 60:205-22.

33 Gerver WJM, Bruin RD. Relationship between height, sitting height and subischial leg length in Dutch children: presentation of normal values. Acta Paediatr 1995;84:5325.

34 Tanner JM, Hayashi T, Preece MA, et al. Increase in length of leg relative to trunk in Japanese children and adults from 1957 to 1977: comparison with British and with Japanese Americans. Ann Hum Biol 1982;9:411-23.

35 Kandel DB, Wu P, Davies M. Maternal smoking during pregnancy and smoking by adolescent daughters. Am $\mathcal{F}$ Public Health 1994;84:1407-13.

36 Power C, Fogelman K, Fox AJ. Health and social mobility during the early years of life. Quarterly fournal of Social Affairs 1986;2:397-413.

37 Brown DC, Byrne CD, Clark PMS, et al. Height and glucose tolerance in adult subjects. Diabetologia 1991:34: 531-3.

38 Njølstad I, Arnesen E, Lund-Larsen PG. Sex differences in risk factors for clinical diabetes mellitus in a general population: a 12-year follow-up of the Finnmark Study. Am 7 Epidemiol 1998;147:49-58.

39 Sayeed MA, Banu A, Khan AR, et al. Prevalence of diabetes and hypertension in a rural population of Bangladesh. Diabetes Care 1995;18:555-8.

40 Colditz GA, Willett WC, Stampfer MJ, et al. Weight as a risk factor for clinical diabetes in women. Am $\mathcal{F}$ Epidemiol 1990; 132:501-13.

41 Yarnell JWG, Patterson CC, Sweetnam PM. Simple measure of insulin resistance. Lancet 1995;346:1108-9.

42 Yarnell JWG, Patterson CC, Bainton D, et al. Is metabolic syndrome a discrete entity in the general population? Evidence from the Caerphilly and Speedwell population studies. Heart 1998;79:248-52.

3 Davey Smith G, Hart C, Blane D, et al. Adverse socioeconomic conditions in childhood and cause-specific adult mortality: the Renfrew and Paisley study. BMF 1998; 316:1631-5.

44 Davey Smith G, Hart C. Insulin resistance syndrome and childhood social conditions. Lancet 1997;9047:284-5.

45 Buckler JMH. Growth at adolescence. In: Kelnar CJH, Savage MO, Sterling HF, et al. Growth disorders. London: Chapman and Hall, 1998.

46 Frankel S, Gunnell DJ, Peters TJ, et al. Childhood energy intake and adult mortality from cancer: the Boyd Orr cohort study. BMF 1998;316:499-504. 